\title{
Representing Dialectic and Regional Lexicon in Explanatory Dictionaries of Albanian Language
}

\author{
Polite Çoçka
}

Aristidh Çipa

Candidates of Doctorature, The Centre of Albanologic Studies in Tirana, Albania, Institute of Albanian Language Tirana, Albania; Email: politecocka@hotmail.com; Email: aristidhcipa@hotmail.com

Doi:10.5901/ajis.2016.v5n3s1p61

\begin{abstract}
Dialectic and regional lexicon has been and would continue to be a precious and inexhaustible resource for the standard literal Albanian language. Albanian language has got two dialects the Gheg and the Tosk. Both dialects meet together along the Shkumbin river, respectively on the right the Gheg dialect is spoken and on the left prevails the Tosk dialect. Both dialects are similar and alike to each other, so that they have always been Albanian language variants, used to write different works. This situation continued until the period of consolidation of Albanian language with the Orthographic Congress in 1972. The main principal of the Albanian language Congress was to represent the Albanian language with a common variant, with the same language for all Albanians in and out of the country borders. This could be done only with the standard literal language. The Orthographic Congress, with its achievements, makes an important irreversible turn in the history of the Albanian language. On the other hand, the processing of the standard Albanian language, did not have a negative affect upon the improvement and the development of dialects and regional language. All these changes have been clearly represented in explanatory dictionaries of Albanian language. Presentation of dialectisms and regionalisms from one dictionary to another, has been different because of the time and the linguistic circumstances on which they have been published. If we drop a look on all explanatory dictionaries of Albanian language, on a comparative plan, we will notice clear differences.
\end{abstract}

Keywords: Albanian language, dialects, word, explanatory dictionary.

The first reliable Albanian dictionary, published in 1954, is characterised by a tendency which represents a lexicon that aims towards the standard, but not being able to reach the quality and quantity level of oncoming dictionaries, eventhough it was compiled and published before the Orthographic Congress.

Important considerable changes have accured with the lexical fund of explanatory Albanian dictionaries after the Orthographic Congress held in 1972.

Already, a great number of words, once called part of this or that dialect, were now words of a common Albanian language. They had left behind the previous status of the dialect they belonged to, and had thus, won a wider status, the nation- wide one.

So, the development of life in all fields, mainly in the field of education, culture and science also the development of the literal language itself, led to the compile of a new explanatory dictionary , as standard as possible, with a wider and systematic range of words, with a richer phraseology and greater scientific needs.

"The Dictionary of Modern Albanian Language" is overwhelmed by a new theoretical evaluation of linguistic standard, words, phraseology of sayings and the meaningful content of the word. In it, it is greatly embodied the Albanian language, as the only literal national language, common and standardized, with defined features and with clear improving/ developing tendencies. Furthermore, in this dictionary, it is also widely expressed the codification of lexical standard and the application of the morphological, orthographic and Orthoepy standard.

The dictionary of the modern Albanian language introduces the lexical composition of the Albanian language at that time, as well as the literal forms of each word; the main grammatical categories of the word; the warning of the word as a lexical - grammatical unit; expressive and stylistic emotions that make it different in different speeches.

During the two or three last decades of the XX century the Albanian language had a great burst. Its lexicon was confronted with continuous changes: on one side the values of the vivid popular source were widely used, inherited from the written language, and, on the other hand thousands of new words and expressions were created using the language's own staff.

Many words were expanded with new meanings and new meaningful connotations. Many words were no longer 
used and they lost their previous vividness. All these brought about a quick increase in the number of words and expressions in Albanian language, as well as moving, enriching and distinguishing the meaningful and functional values of the phraseology and lexical units.

In the introduction of the 'The Dictionary of the Modern Albanian Language' are introduced its two main duties: a) giving explanations and normative for the word usage as well as expressions had been established into the Albanian language up to the time when they came out of use. b) bringing into use words or expressions very little known or unknown, especially those of popular source, which up to that time had not been represented in dictionaries or other publishing, but which had all values and possibilities to become part of the lexical and phraseological fund of the literal national language.

Despite the active lexicon, the 'Dictionary of the Modern Albanian Language' also includes some word categories and expressions with a more limited usage. Here are included words related to history connected with the past of the Albanian people, words which belong to designated fields of agricultural, livestock and craft production or words that have been closely connected with the lifestyle of regions, plants popular medicine and up to different religions and mythologies.

All Albanian words and phraseological units in the "Dictionary of Modern Albanian Language " have been considered as a common, cultural treasure of Albanian people. The evaluation of each lexical unit and each expression, is not based on the regional or literal source, but according to the real value it has had in the lexical structure of the national literal language. The word has been seen under a critical point of view: how will it serve to enrich the literal lexicon, how much it will help to deepen the purity of the literal Albanian language or enlarging the range of stylistic or expressive tools. Also, the word has been studied in comparison with the lexical strata increasing and developing as well as those that go towards coming out of use. ${ }^{1}$

The same attitude has been held by the other explanatory dictionaries, for example the 1984 dictionary, as well as "The Albanian Language Dictionary", 2006. Despite the active lexicon, which involves the majority of the vocabulary, a small part is considered to be the passive vocabulary with historic terms, dialectisms, regionalisms and archaisms. In explanatory dictionaries of Albanian language historic terms have been marked with the abbreviation "hist.", regional expressions or words have been marked with the abbreviation "krahin.", whereas words rarely used are marked with the abbreviation "rrallë".

Referring to a statistical study done for the number of regionalisms in each dictionary it was emphasised that: In "The Modern Albanian Language Dictionary" (1980) there are nearly 1001 regional words, in "The Dictionary of Modern Albanian Language" (1984) there are nearly 246 regional words, whereas in "The Albanian language Dictionary" (2006), are treated almost 222 regional words.

Thus, regionalisms, in the explanatory dictionary of the 80 's occupy about $2.38 \%$ compared to the whole lexicon treated, $0.7 \%$ occupy in the dictionary of 84 's and finally in the dictionary of 2006 the regional words comprise only $4.6 \%$ of the whole vocabulary. Also, if we refer only to the vocabulary of the letter $\mathrm{K}$ in all three explanatory dictionaries of Albanian language, we find out these data:

\begin{tabular}{|l|c|c|c|}
\hline Dictionaries & Vocabulary of the letter K & Number of regionalisms & $\%$ \\
\hline The Dictionary of Modern Albanian language & 3408 & 49 & 1.43 \\
\hline The Dictionary of Modern Albanian & 2749 & 10 & 0.36 \\
\hline The Dictionary of Albanian language & 2475 & 19 & 0.76 \\
\hline
\end{tabular}

As we can distinguish, the numbers of regionalisms is different from one dictionary to another. Reasons are directly connected with the criteria applied to compile each dictionary.

Most regionalisms that exist in "The Dictionary of Modern Albanian Language" are missing in other dictionaries. For example: abe, abuz, kaçi, kafkallë, kanavetë, kapinë, karriq, karrtet, kashër, katapi, katarak, këllfishte, kishk, kishkë, kitë, klitë, koci, kopran, korropesh etc. Whereas a part of them exists both in "The Dictionary of Modern Albanian Language" and "The Dictionary of Albanian Language" but not as regionalisms, but as words of the active lexicon, for example: kakëzogëz, kallume, kolovajzë,korit (koris) etc. In this group there will be also included even those words that appeared as regionalisms, not in their primary meaning, but in other meanings. There are cases when regionalisms appear as such in the explanatory dictionaries of 1980 and 2006, but not in the explanatory dictionary of 1984.These words in "The Modern Albanian dictionary" (1984) appear without the note "regionalisms", for example: kall, kopresh. 
This usage seems to be unusual and strange, but the reason could be the treatment of these words in different ways."The Modern Albanian Dictionary"and "The Albanian Dicionary" might have treated them as regionalisms whereas "The Dictionary of Modern Albanian" might have treated them as words which have passed on the active strata of the lexicon.

With the passing of time, many words have been substituted by active strata of the lexicon in stead of the passive ones. Words slowly lose their expressing and meaningful power, which brings about the reduction of their usage in speech and in writing.After being widely used, most words change into regionalisms, later into archaisms up to rare words. This is a very frequent phenomena that appears in all explanatory Albanian dictionaries. Respectively, many words presented as active words in the explanatory dictionaries of 1980 \& 1984, are seen as part of the regional lexicon in the last dictionary of 2006 , or othervise they are seen as regionalisms. For example: kaptinë, karpuz, katinar, konop, kumi etc.

Regional lexicon, in all explanatory dictionaries of Albanian language, belongs to different fields that are directly connected with life styles and the way of thought.

Every region has its own customs and traditions, different from one another, whose features are represented quickly in the lexicon of each area.

The fields, in which the regionalisms have been mostly used in explanatory Albainian dictionaries are: medicine field,flora, fauna as well as the world of traditional cooking typical clothing, everyday expressions, wishes, curses up to the names of different people or things.

drop, $-i^{2} m$. krahin. a dessert with crumbs of bread fried in butter: drop with almonds.

gjol-i ${ }^{3}$ m. sh. -e(t) 1. krahin. lake; marshes: gjoli i Pogradecit. 2. Deep mud; thin mud.

kall ${ }^{4}$ kal., -a, -ur krahin. light: kall a ciggarette. •kállet vetv. v. III is lit. / passive. kállet $v$. III. • kállj/e,-a $f$. lighting. -kallur (i, e) adj. lit.

përmjét, $-i^{5} \mathrm{~m}$. krahin. waist.

vég/ë,--a ${ }^{6}$. krahin. 1. edhe fig., vjegë. 2. leg: me vegë të holla.(with thin legs)

Another topic that arises interest concerning regional words and their position in Albanian explanatory dictionaries in the semantic spectrum or differently set, the semantic structure.

If we compare the semantic explanations from one dictionary to another we will distinguish the tendency of the latest explanatory dictionaries to be abstract at a higher level or degree, based defenitely on the semantic similarities of the main parts.

\footnotetext{
${ }^{2}$ The Dictionary of Albanian Language, Tirana, 2006, f. 218.

${ }^{3}$ The Dictionary of Albanian Language, Tirana, 2006, f. 360.

4The Dictionary of Albanian Language, Tiran, 2006, f. 432.

${ }^{5}$ The Dictionary of Albanian Language Tiranë 2006, f. 797.

${ }^{6}$ The Dictionary of Albanian Language Tiranë 2006, f. 1160.
} 